\title{
What do parents want from their child's asthma treatment?
}

\author{
Stefan Walzer \\ Analytica International, Untere \\ Herrenstrasse 25, 79539 Loerrach, \\ Germany
}

Background: Nearly 5 million children in the United States are affected by asthma, which is more than $5 \%$ of the population younger than 18 years. In children four years or younger, the prevalence increased 160\% from 1980 to 1994 . There are several effective drugs that relieve the symptoms of asthma and others are currently being developed, but even when these medications are prescribed, they may be underutilized because parents fear the possibility of adverse events. Up to now there is no knowledge which are the main drivers of caregiver's preferences for a safe and effective medication for preschool children in general. The study population was caregivers with children aged 4 years or below. Sample size was 42; results were checked by Monte Carlo simulation.

Material and methods: For a conjoint analysis a status quo treatment and hypothetical treatment options were defined by four attributes: Episode-free days, risk of exacerbation, information available for the long-term impact of the treatment, and out-of-pocket expenses. It was possible to use the status quo as the reference scenario, permitting to couch this ranking in terms of a decision to purchase the product. Relative importances for each product attribute as well as utility estimations for each attribute level were calculated.

Results and discussion: The overall result was that the most important feature for an asthma treatment, in this study, was the attribute of episode-free days. On a scale from 0 to 100 this attribute got the calculated relative importance of 44.2. In contrast to this finding is the relative importance of the attribute EXACERBATION, which only reached 16.2, which is the most unimportant attribute of the attributes offered. Even the variable INFORMATION available on long-term effects in children between 4 years and 14 years of age was more important than the side effects (19.2). Out-of-pocket expenses per month were the second most (relative) important attribute (20.5).

Keywords: utility, conjoint analysis, preference study, health economics, discrete-choice analysis

\section{Introduction}

Asthma is a chronic disease that effects between 9 and 12 million persons in the US (Weiss et al 1992) and is the most common chronic disease of childhood (CDC 2000). Nearly 5 million children in the US are affected by asthma, which is more than $5 \%$ of the population younger than 18 years (Adams and Marano 1994). It is the leading cause of lost school days in children (Taylor and Newacheck 1992; NHDS 1993). In children four years or younger, the prevalence increased 160\% from 1980 to 1994 . To avoid the missing school days preschool children should be treated in the most effective way as possible. There are several effective drugs that relieve the symptoms of asthma and others are currently being developed but even when these medications are prescribed, they may be underutilized because parents fear the possibility of adverse events and long-term effects. Up to now there is no knowledge which are the main drivers of caregiver's preferences for a safe and effective medication for preschool children in general. 
Asthma or wheezing conditions was not explicitly defined. Respondents were screened based on the asthma medication that the child is currently taking for the treatment of the condition. Severity of asthma/wheezing condition was identified by applying the "Evaluation of a short form for measuring health-related quality of life among pediatric asthma patients".

For an economic evaluation (such as a preference study) of treatments in diseases such as asthma, where a substantial impact is on quality of life rather than survival, it is crucial to be able to incorporate the effects of the new therapies on quality of life and include those effects in the economic evaluation. Within healthcare there is substantial evidence to suggest that, in addition to the treatment outcome (that is, the effectiveness), other aspects of the process of receiving treatment are also important for individuals (Ryan and Hughes 1997; Balsbaugh et al 1999; Ratcliffe and Buxton 1999; Ryan 1999; Johansson et al 2004). Conjoint analysis was originally developed for market research into consumer preferences, and is a method that investigates the relative importance of groups of attributes, eg, products with certain properties or more abstract concepts such as treatment procedures (Green and Rao 1971; Srinivasan and Shocker 1973). It has been applied to various aspects of healthcare (see Ryan 1996; Szeinbach et al 1999). The method can thus be used to analyze patient preferences for various treatment alternatives.

No asthma treatment regimen is likely to have all the attributes that patients would ideally like; for example, a regimen might be highly effective (desirable) but expensive (undesirable). Conjoint analysis provides a method of "trading off" desirable attributes against undesirable ones, and assessing which attributes are most important in determining the patient preferences for one regimen over another. The target population of this study is preschool children with a maximum age of 4 years. Obviously the possibility of asking the children was naturally limited and hence the caregivers answered for them.

The purpose of this study was to evaluate, using conjoint analysis, asthma patients' preferences for different aspects of asthma treatment, including efficacy (episode-free days), side effects (risk of exacerbation), available information by the Food and Drug Administration (FDA) about long-term effects, and out-of-pocket expenses. The relative importance was evaluated for each of the described attributes.

\section{Materials and methods}

The methods used for the discrete choice part of this study were already explained in a recent paper (Walzer and Zweifel 2007). The study protocol was conducted in accordance with the Declaration of Helsinki and approved by local ethics committees, and all participants gave written informed consent.

It is assumed that the preferences of caregivers of preschool children with asthma could be taken as approximations for the utility of their child for a given treatment. If the caregiver is a pure altruist with respect to the child, ie, cares for the child, but respects the child's preferences, the caretaker's responses will reflect the child's preferences. For the present analysis caregivers were asked to choose between two hypothetical asthma treatments for their child. The decision was based on a status quo treatment versus a new (hypothetical) treatment with changed attribute levels. Possible attributes and their levels were tested in various face-to-face interviews with caregivers in autumn 2005. Potential and actual study participants were contacted based on information from a consumer database in the US. The tested attributes were ease of handling, efficacy (episode-free days), time for administration, number of administrations per day, side effects (risk of asthmatic exacerbation), available information by the FDA (information on long-term effects in children between 4 and 14 years of age), as well as expenses. This pre-test was deducted mainly as qualitative interviews with seven applicants (see Table 1). It was found that the main attributes for the treatment of asthma were expenses, episode-free days, side effects, and available information by the FDA.

Pre-test interviews resulted in the fact that the main attributes for the treatment of asthma were expenses, episode-free days, side effects, and available information by the FDA (Walzer and Zweifel 2007).

In conjoint analysis, several attributes of treatment are selected and a range of possible values ("levels") are defined for each attribute (Ben Akiva and Lerman 1985). These are used to create a number of treatment concepts, each with different levels for the various attributes. The levels of attributes were defined as follows (see Table 1): 'Episodefree days' (FREEDAYS), symbolizing the change in the risk to develop asthma attacks from an unknown individual level, takes on changes from 180 days (baseline [Pauwels et al 1997]) to 200 and 220 days per year as well as a possible decrease in change to 160 and 140 days per year. 'Exacerbation' (EXACERBATION), defined as developing 
Table I Product attributes and levels retained in the main survey

\begin{tabular}{|c|c|c|c|}
\hline Attributes & Label & Levels & $\begin{array}{l}\text { Value } \\
\text { labels }\end{array}$ \\
\hline \multirow[t]{4}{*}{ Episode-free days } & FREEDAYS & Increase from I 80 to 200 episode-free days per year & 200 \\
\hline & & Increase from I 80 to 220 episode-free days per year & 220 \\
\hline & & Decrease from 180 to 1600 episode-free days per year & 180 \\
\hline & & Decrease from 180 to 140 episode-free days per year & 140 \\
\hline \multirow[t]{3}{*}{ Exacerbation } & EXACERBATION & Risk of EXACERBATION: $6 \%$ of patients develop a mild to severe EXACERBATION & 6 \\
\hline & & Risk of EXACERBATION: I0\% of patients develop a mild to severe EXACERBATION & 10 \\
\hline & & Risk of EXACERBATION: I6\% of patients develop a mild to severe EXACERBATION & 16 \\
\hline $\begin{array}{l}\text { Information about } \\
\text { long-term effects by }\end{array}$ & INFORMATION & $\begin{array}{l}\text { INFORMATION available on long-term effects in children between } 4 \text { years and } \\
\text { I } 4 \text { years of age }\end{array}$ & 1 \\
\hline the FDA available & & $\begin{array}{l}\text { No INFORMATION available on long-term effects in children between } 4 \text { years and } \\
\text { I4 years of age }\end{array}$ & 2 \\
\hline Out-of-pocket & EXPENSES & $\$ 10$ per month & 10 \\
\hline \multirow[t]{2}{*}{ EXPENSES } & & $\$ 30$ per month & 30 \\
\hline & & $\$ 50$ per month & 50 \\
\hline
\end{tabular}

Abbreviations: FDA, Food and Drug Administration.

mild or moderate exacerbation, varies between levels of $6 \%$, $10 \%$, and $16 \%$. A recent study with adults has shown that mild to moderate asthmatic patients are very much affected by their disease and patient's utility was decreasing when developing an exacerbation (Andersson et al 2003). It is assumed that these findings are also valid in preschool children. For the FDA 'information' on long-term effects (INFORMATION) in children between 4 and 14 years of age, two levels were used: Availability or nonavailability. Other studies have shown that caregivers could be concerned about the missing long-term effects of asthma treatment in preschool children (de Jongste et al 2002). The 'out-ofpocket cost' (EXPENSES) per month ranges from $\$ 10, \$ 30$, to $\$ 50$. Status quo treatment (see Table 2) was defined as having 180 episode-free days per year and a risk to develop a mild or severe exacerbation of $10 \%$. Information by the FDA is available and the monthly out-of-pocket expenses are $\$ 20$.

Since the second and the last attributes have 3 levels each, while FREEDAYS has 4 and INFORMATION has 2, the number of scenarios amounts to a total of 72 (= $4 * 3 * 2 * 3$ ). Techniques have been developed to reduce the number of possible scenarios while still being able to infer utilities for all combinations of levels of the attributes (Louviere et al 2000). Using the ORTHOPLAN procedure, which implicitly assumes a linear utility function, programmed in the software package SPSS (SPSS Inc, Chicago, Illinois, USA), the design was reduced to 16 scenarios. All study participants had to answer these 16 variants as well as two hold-out cards whereas the scenarios were randomly assigned to take care of a possible question ordering bias (Mitchell and Carson 1989). With regard to each variant, respondents had to indicate whether or not they would choose the treatment and would pay the monthly out-of-pocket expenses (see Appendix A1 for a sample card presented to study participants).

\section{Results \\ Descriptive statistics}

Descriptive statistics of the caregivers with regard to the dependent and explanatory variables are reported in Table 3. Nearly all caregivers who took part in the survey were female $(92.9 \%)$. The average of the respondents have one child. Caregivers were also asked how confident they are in knowing what they do when they are thinking about their overall ability to take care of their family's general health: eating right, getting check-ups, taking medicine, or deciding when to see the doctor. Within the whole population, $42.9 \%$ agreed with the statement of feeling "Very confident" and another $26.7 \%$ agreed with the statement of feeling "Extremely confident". Summarized, 31\% felt fairly and/

Table 2 Status quo treatment: definition by attribute levels

\begin{tabular}{ll}
\hline Attributes & Levels \\
\hline Episode-free days & $\begin{array}{l}\text { I80 episode-free days per year } \\
\text { Risk of EXACERBATION: } 10 \% \text { of } \\
\text { EXACERBATION }\end{array}$ \\
$\begin{array}{l}\text { EXACERBATION develop a mild to severe } \\
\text { INFORMATION available on long-term } \\
\text { INFORMATION availability }\end{array}$ \\
$\begin{array}{l}\text { IN in children between } 4 \text { years and } \\
\text { Out-of-pocket EXPENSES }\end{array}$ & $\$ 20$ per month \\
\hline
\end{tabular}


Table 3 Descriptive statistics of caregivers

Percent $\begin{array}{r}\text { Cumulative } \\ \text { percentage }\end{array}$

\begin{tabular}{l}
\hline Gender \\
Female \\
Age \\
$<30$ years \\
$30-39$ years \\
$40-49$ years \\
$>50$ years \\
Number of children $\leq 4$ years \\
I child \\
2 children \\
Rating of healthcare \\
Fairly/somewhat confident \\
Very/extremely confident \\
Number of children with diagnosed \\
asthma and/or wheezing conditions \\
I child
\end{tabular}

I child

2 children

92.9

28.6

42.8

19.1

9.5

71.4

90.5

73.8

26.2

100

Relationship to children

Mother or female guardian

Father or male guardian

Grandparent

Level of education

High school graduate (or lower)

Some college

Associate/Bachelor's degree

Postgraduate school

Current employment situation

Working full-time

Working part-time

Homemaker

Annual household income in 2004

$<$ US $\$ 25000$

US\$25 000-49999

US\$50 000-74999

$>$ US $\$ 75000$

Smoking

Smoker

Nonsmoker

Severity estimation by caregiver

Very mild

Mild

Moderate

Severe

Severity diagnosis by physician

Mild

Moderate

Severe

Doctor never told me the severity

Compliance estimation for other caregivers

$<20 \%$

$20 \%-39 \%$

$40 \%-59 \%$

$>60 \%$

31.0

69.0

100

73.8

26.2

85.7

7.1

7.1

92.9

100

11.9

31.0

40.5

14.3

42.9

83.3

40.5

11.9

45.2

4.8

45.2

19.0

23.8

28.6

71.4

21.4

35.7

40.5

2.4

57.1

97.6

100

35.7

40.5

4.8

19.9

76.2

81.0

100

Note: $*$ Other education: $2.4 \%$; **Retired: $2.4 \%$; ***Declined to answer: $7.1 \%$; *****Don't know: $2.4 \%$
Table 3 Continued

\begin{tabular}{lll}
\hline & Percent & $\begin{array}{r}\text { Cumulative } \\
\text { percentage }\end{array}$ \\
\hline Own compliance estimation & & \\
$<10 \%$ & 76.2 & 88.1 \\
$10 \%-19 \%$ & 11.9 & 92.9 \\
$20 \%-29 \%$ & 4.8 & 100 \\
$>30 \%$ & 7.1 & \\
Children characteristics & & \\
Age & & \\
$\leq 2$ years (child I) & 33.3 & \\
$\leq 2$ years (child 2) & 0 & \\
Gender & & \\
Female (child I) & 35.7 & \\
Female (child 2) & 66.7 & \\
Race & & \\
White & 88.1 & \\
Black & 4.8 & \\
Other & 7.1 & 100
\end{tabular}

Medications currently taken (more than one drug could be chosen)

Accolate $\quad 2.4$

Advair $\quad 2.4$

Flovent 7.I

Pulmicort Respules $\quad 28.6$

Singulair $\quad 76.2$

Prevalence of asthma 88.1

Prevalence of wheezing conditions 26.2

Prevalence of allergies $\quad 71.4$

Cough in last 4 weeks

Never

Some days

Most days $\quad 19.0$

Every day 11.9

Wheezing conditions in last 4 weeks

Never $\quad 26.2$

A few days $\quad 33.3$

Some days $\quad 35.7$

Every day 2.4

Shortness of breath in last $\mathbf{4}$ weeks

Never 57.1

A few days $\quad 16.7$

Some days $\quad 19.0$

Most of the days

4.8

Asthma attacks in last $\mathbf{4}$ weeks

Never

85.7

A few days $\quad 9.5$

Some days 2.4

Most of the days 2.4

Number of asthma attacks in last 4 weeks

$\begin{array}{ll}0 & 16.7\end{array}$

I attack $\quad 50.0$

2 attacks $\quad 16.7$

6 attacks $\quad 16.7$

45.3

69.1

88.1

100

59.5

95.1

$97.6 * * * *$

Awakened in last 4 weeks due to asthma/wheezing conditions Never

A few days $\quad 40.5 \quad 78.6$

$\begin{array}{lll}\text { Some days } & 16.7 & 95.2\end{array}$

Most of the days

4.8

\section{8}

92.8

$97.6 * * * *$

95.2

97.6

100

66.7

83.3

100 
or somewhat confident and $69 \%$ of caregivers felt very and/ or extremely confident.

In $18 \%$ of cases, the doctor never told the caregiver the asthma severity diagnosis of their child. Of caregivers, $21.4 \%$ rated the severity of their child as very mild, whereas no physician diagnosed a child with that rate. Differences in diagnosing severe asthma could be detected: $4.8 \%$ of physicians diagnosed children as having severe asthma whereas only $2.4 \%$ of caregivers made the same diagnosis.

Caregivers were also asked about their estimation of how many caregivers (in general) forget to provide the asthma medication for their child during a week due to several reasons (job stress, care for other children, etc.) in one week on average. In various studies it turned out that up to $95 \%$ of caregivers (on average around 50\%) don't give the medication in the right way (not regularly, wrong dosage, etc.) (Gibson et al 1995; Moy et al 2004). Study respondents estimated that $16.7 \%$ of other caregivers never forget to administer medication per week. It was estimated by $54.8 \%$ of study respondents that a maximum of $19 \%$ forget to medicate their child. But when asking in how many cases the caregivers themselves forget it, $88.1 \%$ of study respondents said that they themselves forget to ask at a maximum of $19 \%$. When estimating for other caregivers, the cumulative of $88 \%$ is reached for around $69 \%$ of caregivers who will forget to offer the (correct) treatment, which is nearly the number that could be found in the literature.

The medications children were currently taking for the treatment of asthma and/or wheezing conditions are distributed in this sample as follows, whereas more than one drug could be taken for treatment: $76.2 \%$ are taking Singulair; 28.6\% Pulmicort Respules; 7.1\% Flovent; Accolate; and Advair are taken by $2.4 \%$ respectively. During the last 4 weeks in advance of the survey, $23.8 \%$ of children have experienced cough on some days whereas $19 \%$ experienced this complication most days. Cough was experienced every day by $11.9 \%$ of children. The condition wheezing was less often experienced every day (2.4\%) but nearly $33 \%$ experienced wheezing for a few days in the last 4 weeks. Caregivers reported that $57.1 \%$ of their children never had shortness of breath, but $19 \%$ reported that their children experienced that symptom some days in the last month. Asthma attacks in this study population were not that frequent (never experienced in the last 4 weeks: $85.7 \%$ ) with experiences of this symptom a few days in $9.5 \%$. Of those who experienced asthma attacks, 50\% had one attack in the last month, $16.7 \%$ had two, and another $16.7 \%$ had six asthma attacks. The possibility of awakening during the night due to asthma/wheezing conditions, such as asthma attacks, etc., was relatively frequent but not that severe: $38.1 \%$ never awakened, 40.5\% awakened a few nights, $16.7 \%$ some nights, but also $4.8 \%$ awakened each night.

Most or all the time treatment choices were offered to the caregivers by $52.4 \%$ of pediatricians of these children (Table 4). While they were doing so, the physicians also discussed the pros and cons of the offered/suggested treatments. After discussions with caregivers, they stated that pediatricians take their preferences into account when making treatment decisions for their child's asthma or wheezing conditions care. This could be taken as an indication that these caregivers should be interested in available information by the FDA on long-term effects. Additionally, $85.7 \%$ of caregivers reported to follow the asthma or wheezing conditions medication schedule given to them by their child's doctor or nurse. On the other hand, around $90 \%$ mentioned that they provide medications to their child when they feel it was appropriate.

Table 4 Treatment behavior of caregivers

\section{Percent Cumulative}

percent

\begin{tabular}{|c|c|c|}
\hline \multicolumn{3}{|c|}{$\begin{array}{l}\text { Physician offers treatment } \\
\text { wheezing conditions care }\end{array}$} \\
\hline All of the time & 28.6 & \\
\hline Most of the time & 23.8 & 52.4 \\
\hline Some of the time & 28.6 & 81.0 \\
\hline A little of the time & 2.4 & 83.3 \\
\hline None of the time & 16.7 & 100 \\
\hline \multicolumn{3}{|c|}{$\begin{array}{l}\text { Physician discusses the pros and cons of each treatment } \\
\text { choice with you }\end{array}$} \\
\hline All of the time & 35.7 & \\
\hline Most of the time & 33.3 & 69.0 \\
\hline Some of the time & 9.5 & 78.6 \\
\hline A little of the time & 7.1 & 85.7 \\
\hline None of the time & 14.3 & 100 \\
\hline \multicolumn{3}{|c|}{$\begin{array}{l}\text { Physician takes your preferences into account when making } \\
\text { treatment decisions for your child }\end{array}$} \\
\hline All of the time & 35.7 & \\
\hline Most of the time & 40.5 & 76.2 \\
\hline Some of the time & 9.5 & 85.7 \\
\hline A little of the time & 4.8 & 90.5 \\
\hline None of the time & 9.5 & 100 \\
\hline \multicolumn{3}{|c|}{$\begin{array}{l}\text { I follow the asthma or wheezing conditions medication } \\
\text { schedule given to me by my child's doctor or nurse }\end{array}$} \\
\hline Yes & 85.7 & \\
\hline No & 14.3 & 100 \\
\hline \multicolumn{3}{|c|}{$\begin{array}{l}\text { I provide asthma or wheezing conditions medication(s) to } \mathrm{my} \\
\text { child when I feel is appropriate }\end{array}$} \\
\hline Yes & 90.5 & \\
\hline No & 9.5 & 100 \\
\hline
\end{tabular}




\section{Conjoint analysis}

Results from the discrete choice decisions served as a basis for a conjoint analysis (Green and Rao 1971). Relative importance for each product attribute as well as utility estimations for each attribute level was calculated.

For the caregivers, the key attribute for an asthma drug for the treatment of childhood asthma is FREEDAYS. On a scale from 0 to 100 this attribute got the calculated relative importance of 44.2 (Figure 1). In contrast to this finding is the relative importance of the attribute EXACERBATION, which only reached 16.2 , which is the most unimportant attribute of the attributes offered. Even the variable INFORMATION available on long-term effects in children between 4 years and 14 years of age was more important than the side effects (19.2). Out-of-pocket expenses per month were the second most (relative) important attribute, whereas it was only slightly more important than the attribute INFORMATION (20.5).

The utilities for the efficacy attribute (FREEDAYS) are positive for the increase of episode-free days and negative for the decrease of episode-free days (Table 5). However, the utility is not increasing with the increasing number of episode-free days. With decreasing episode-free days, the utilities are also decreasing. The utilities for the increasing out-of-pocket EXPENSES were decreasing with the growing costs. Furthermore the utility for the available information is positive and vice versa.

The conjoint analysis' findings were also tested for its possibilities to predict the observed values: Pearson's R was relatively good (0.73) as well as Kendall's tau (0.54),

Table 5 Conjoint analysis: Utility estimations (Base Case)

\begin{tabular}{lll}
\hline & $\begin{array}{l}\text { Utility } \\
\text { Estimate }\end{array}$ & $\begin{array}{l}\text { Standard } \\
\text { Error }\end{array}$ \\
\hline FREEDAYS & & \\
Increase episode-free days I80 to 200 & 0.057 & 0.038 \\
Increase episode-free days I80 to 220 & 0.039 & 0.038 \\
Decrease episode-free days I80 to I60 & -0.045 & 0.038 \\
Decrease episode-free days I80 to I40 & -0.05 I & 0.038 \\
EXACERBATION & & \\
6\% develop an EXACERBATION & 0.036 & 0.027 \\
I0\% develop an EXACERBATION & 0.07 I & 0.053 \\
I6\% develop an EXACERBATION & 0.107 & 0.080 \\
INFORMATION & & \\
INFORMATION available & -0.060 & 0.044 \\
No INFORMATION available & -0.119 & 0.088 \\
EXPENSES & & \\
\$I0 & -0.018 & 0.027 \\
\$30 & -0.037 & 0.053 \\
\$50 & -0.055 & 0.080 \\
(Constant) & 0.116 & 0.096 \\
\hline
\end{tabular}

Table 6 Conjoint analysis: Correlations between observed and estimated preferences

\begin{tabular}{lll}
\hline & Value & Sig. \\
\hline Pearson's R & 0.703 & 0.001 \\
Kendall's tau & 0.543 & 0.002 \\
Kendall's tau for holdouts & 1.000 & 0.0 \\
\hline
\end{tabular}

whereas both measures were highly significant for the correlation between the observed and predicted values (Table 6). Furthermore Kendall's tau for the hold-out cards is 1 .

\section{Sensitivity analysis}

Due to budget restrictions, only 42 respondents could be included in this survey. However, to improve the validity and significance of the study, the data have also been simulated by 100 Monte Carlo iterations (Vose 2001). Monte Carlo simulations are reproducing data dependent on the input data and their corresponding distributions. In this way it can be checked how sensitive the underlying base data are to changes in the inputs. For the simulation the binomial distribution was assumed for the simulation of the outcome "Scenario". For the caregiver's socioeconomic characteristics a beta-pert distribution was assumed to stay within the calculated ranges of the parameters given by the study participants (Drummond et al 2005). It turned out that the ranking for the relative importance of the four attributes is not changed when using 100 iterations (Figure 1), which was used as having 100 respondents. This procedure is stateof-the-art for checking uncertainty around the data in economic evaluation studies (Drummond et al 2005).

\section{Discussion}

This study has investigated patient preferences for different attributes of asthma treatment in preschool children. The overall result was that the most important feature for an asthma treatment in this study was the episode-free days.

The major criticism about the study is the small sample size of 42 respondents. Due to this fact, the results could be biased due to outliers who could be overweighed. Within a larger population the results could maybe more smoothed and outliers would not be overweighed as can be assumed in a small sample size. However in a Monte Carlo simulation study, which was done along that original study using the study data, it turned out that the conjoint results are relatively stable and could give a first impression about preferences for a treatment within such a special population like caregivers of asthmatic children. 


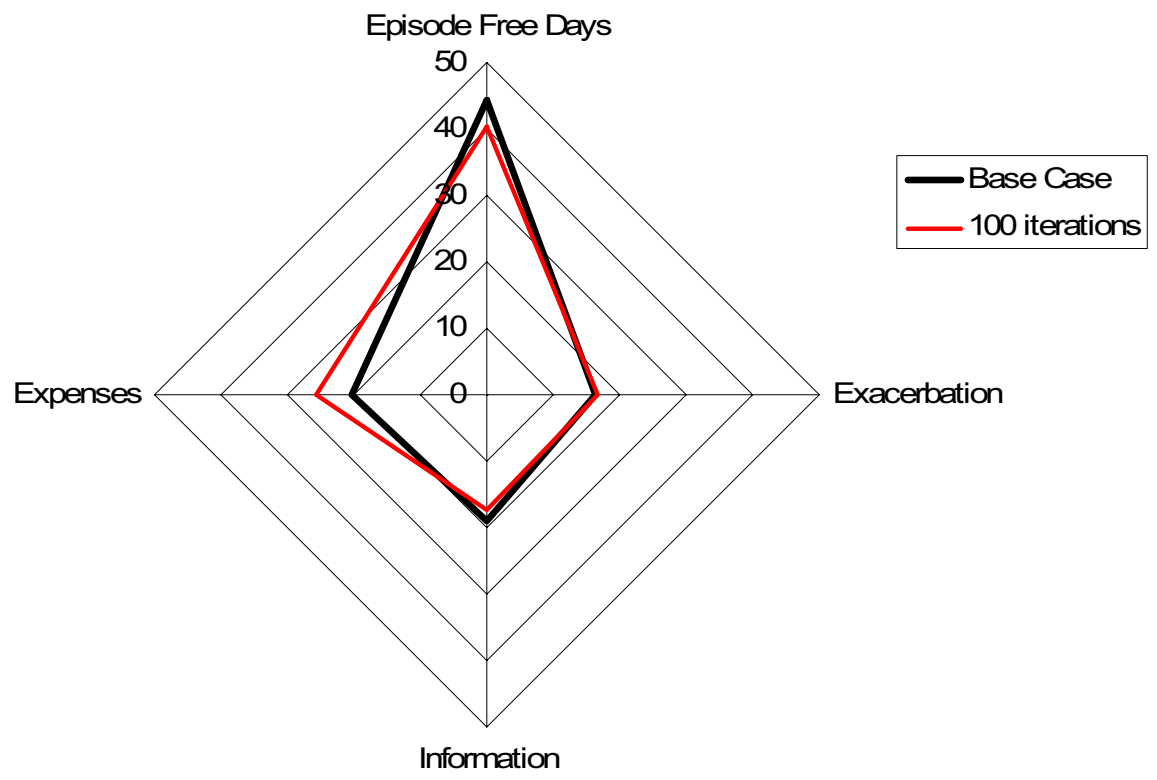

\begin{tabular}{lll} 
& Base Case & 100 iterations \\
\hline FREEDAYS & 44.189 & 40.303 \\
EXACERBATION & 16.181 & 16.667 \\
INFORMATION & 19.153 & 17.362 \\
EXPENSES & 20.477 & 25.668 \\
\hline
\end{tabular}

Figure I Relative importance of factors for treatment of pediatric asthma and/or wheezing conditions. Base Case based on the real number of respondents in comparison to 100 iterations from a Monte Carlo simulation.

The attribute EXACERBATION turned out to be the most unimportant attribute in the base analysis when comparing with the variable INFORMATION available on long-term effects in children between 4 years and 14 years of age. This finding could possibly be explained given that caregivers weight the possible long-term effects, which should be explained by the FDA information, higher than the short-term side effects like the risk of an asthmatic exacerbation. The utilities for each attribute level was in the range as expected with two exceptions: the utility for the efficacy attribute is not increasing with the increasing number of episode-free days. One possible explanation for this could be that the caregivers did not believe that the efficacy would increase by nearly $22 \%$ (possible theoretical misspecification bias [Mitchell and Carson 1989]) from 180 days to 220 days. With decreasing episode-free days, the utilities are also decreasing. Additionally, the finding for the utilities of the risk of exacerbations was also counterintuitive: the higher the probability of an exacerbation, the higher the utility. The relative low importance of that attribute could lead to that finding, ie, that other positive impacts traded out the negative impact of this attribute. Additionally, only few children experienced (very) often shortness of breath or much asthma attacks in the last four weeks in advance of the study. Maybe caregivers are less risk-averse on this attribute when comparing it with the other three. This could be a major caveat of the study, however, the aim of a discrete choice analysis is to have respondents switching between the status quo and the offered (hypothetical) products to calculate the relative importance for the various attributes (Szeinbach et al 1999).

In this application the discrete-choice conjoint analysis requires respondents only to indicate whether they prefer one scenario over another. Moreover, it was possible to use the status quo as the reference scenario, permitting to couch this ranking in terms of a decision to purchase the product. The conjoint method has been used for decades in other research disciplines, notably consumer market research, but has only recently started to be used to study asthma. Osman et al (2001) used conjoint analysis to rank asthma symptoms. Another study (Gibson et al 1995) investigated preferences for a limited number of aspects (need for blood test monitoring, frequency of dosing, and route of administration) for asthma controller medication. To our best knowledge this study is the first one, which analyzed the impact of various treatment attributes on the relative importance of caregivers for their preschool children's asthma treatment. Obviously the sample size is relatively 
small due to budget restrictions. The results should be important in the ranking of attribute importance in preschool children in chronic diseases. Furthermore, the children who participated in the present study are not representative and thus the generalizability of the results is uncertain; eg, the children were typically first-born children with very mild asthma and working mothers with university degrees. Hence the following findings have to be interpreted always in the background of the cohort characteristics. The findings of this study based on the aggregated results from 42 caregivers with children having asthma and/or wheezing condition can be summarized as follows. Caregivers focused primarily on the effectiveness of a treatment (episode-free days). Ranking in terms of importance of expenses, availability of longterm effects, and risk of exacerbation is strongly dependent on the risk aversion of the caregiver.

\section{Acknowledgement}

This study would not have been possible without the expert advise of Prof. Dr. Zweifel from the Socioeconomic Institute of the University of Zurich (Switzerland). I would also like to thank Marcos Memran, who provided support in conducting the survey in the US. There are no relevant conflicts of interest.

\section{Glossary}

Conjoint analysis: Was originally developed for market research into consumer preferences, and is a method that investigates the relative importance of groups of attributes, eg, products with certain properties or more abstract concepts such as treatment procedures.

Product attribute: Attributes are the characteristics of a product, eg, side effects and costs.

Efficacy attribute: Attribute of the product related to the efficacy. Here the efficacy is defined in the study below as 'episode-free days'.

Attribute level: Specification of the product attribute. Usually used by varying the characteristics within realistic levels (eg, attributes for side effects could be low and strong side effects)

Utility estimations: Utilities are a measurement about the importance of a product and/or attribute to the consumers. Usually a utility is a number between 0 and 100 .

Base case: Analysis which is based on the dataset without changing and/or including any assumptions (eg, Monte Carlo simulation).
Beta-pert distribution: Statistical distribution to assume characteristics which are bound between the calculated ranges of the parameters given by the study participants.

\section{References}

Adams PF, Marano MA. 1994. Current estimates from the National Health Interview Survey. Vital Health Stat, 10(193 Pt 1):1-260.

Andersson F, Borg S, Stahl E. 2003. The impact of exacerbations on the asthmatic patient's preference scores. J Asthma, 40:615-23.

Balsbaugh TA, Chambers CV, Diamond JJ. 1999. Asthma controller medications: what do patients want? J Asthma, 36:591-6.

Ben-Akiva M, Lerman SR. 1985. Discrete choice analysis. Cambridge, London: MIT Pr.

[CDC] Centers for Disease Control and Prevention. 2000. Measuring childhood asthma prevalence before and after the 1997 redesign of the National Health Interview Survey-United States. MMWR Morb Mortal Wkly Rep, 49:908-11.

de Jongste JC, Janssens HM, Van der Wouden J. 2002. Effectiveness of pharmacotherapy in asthmatic preschool children. Allergy, 57(Suppl 74):42-7.

Drummond MF, Sculpher MJ, Torrance GW, et al. 2005. Methods for the economic evaluation of health care programmes. Oxford, New York. Oxford Univ Pr.

Gibson NA, Ferguson AE, Aitchison TC. 1995. Compliance with inhaled asthma medication in preschool children. Thorax, 50:274-9.

Green PE, Rao V. 1971. Conjoint measurement for quantifying judgmental data. Marketing Res, 8:355-63.

Johansson G, Ställberg B, Tornling G, et al. 2004. Asthma treatment preference study: A conjoint analysis of preferred drug treatments. Chest, 125:916-23.

Louviere, JJ, Hensher DA, Swait JD. 2000. Stated choice methods analysis and application. Cambridge: Cambridge Univ Pr.

Mitchell RC, Carson RT. 1989. Using surveys to value public goods, the Contingent Valuation Method. Washington, DC: Resources for the Future.

Moy ML, Fuhlbrigge AL, Blumenschein K, et al. 2004. Association between preference-based health-related quality of life and asthma severity. Ann Allergy Asthma Immunol, 92:329-34.

[NHDS] National Hospital Discharge Survey. 1995. Annual summary 1993. Vital Health Stat, 13(121):1-63.

Osman LM, McKenzie L, Cairns J, et al. 2001. Patient weighting of importance of asthma symptoms. Thorax, 56:138-42

Pauwels RA, Lofdahl CG, Postma DS, et al. 1997. Effect of inhaled formoterol and budesonide on exacerbations of asthma. Formoterol and Corticosteroids Establishing Therapy (FACET) International Study Group. N Engl J Med, 37:1405-11.

Ratcliffe J, Buxton M. 1999. Patients' preferences regarding the process and outcomes of life-saving technology. An application of conjoint analysis to liver transplantation. Int J Technol Assess Health Care, $15: 340-51$.

Ryan M, Hughes J. 1997. Using conjoint analysis to assess women's preferences for miscarriage management. Health Econ, 6(3):261-73.

Ryan M. 1996. Using consumer preferences in health care decision making: the application of conjoint analysis; Office of Health Economics. Luton, Bedfordshire, UK: White Crescent Pr.

Ryan M. 1999. Using conjoint analysis to take account of patient's preferences and go beyond health outcomes. An application to invitro fertilisation. Soc Sci Med, 48:535-46.

Srinivasan V, Shocker AD. 1973. Linear programming techniques for multidimensional analysis of preferences. Psychometrika, 38(3):33769.

Szeinbach SL, Barnes JH, McGhan WF, et al. Using conjoint analysis to evaluate health state preferences. Drug Inf J, 33:849-58.

Taylor WR, Newacheck PW. 1992. Impact of childhood asthma on health. Pediatrics, 90(5):657-62. 
Vose D. 2001. Risk analysis: A quantitative guide. 2nd ed. Chichester, New York, Weinheim, Brisbane, Singapore, Toronto: John Wiley \& Sons.
Walzer S, Zweifel P. 2007. Willingness-to-pay for caregivers of children with asthma or wheezing conditions. Ther Clin Risk Manage, 3: xx$\mathrm{XX}$.

Weiss KB, Gergen PJ, Hodgson TA. 1992. An economic evaluation of asthma in the United States. N Engl J Med, 326:862-6.

\section{Appendix}

Appendix 1 An example of a card presented to respondents is shown in Table A1.

Appendix A. I: Example of a card presented to respondents

\begin{tabular}{lll}
\hline & AGENT A & AGENT B (SEE EXCEL) \\
\hline Episode-free days & 180 episode-free days per year & 220 episode-free days per year \\
Exacerbation & Risk of exacerbation: $10 \%$ of patients & Risk of exacerbation: I6\% of patients develop a mild to \\
Information availability & develop a mild to severe exacerbation & severe exacerbation \\
& Information available on long-term effects & Information available on long-term effects in children \\
& in children between 4 years and I4 years & between 4 years and I4 years of age \\
Out-of-pocket expenses & $\$ 20$ & $\$ 50$ \\
\end{tabular}


